\title{
Co-autoria em artigos e patentes:um estudo da interação entre a produção científica e tecnológica ${ }^{1}$
}

Ana Maria Mielniczuk de Moura
Doutora em Comunicação e Informação pelo PPGCOM/UFRGS. Professora do Departamento de Ciências da Informação da Faculdade de Biblioteconomia e Comunicação da UFRGS

Sonia Elisa Caregnato

\begin{abstract}
Doutora em Comunicação e Informação pela Sheffield University. Professora do Departamento de Ciências da Informação e do Programa de PósGraduação em Comunicação e Informação da Faculdade de Biblioteconomia e Comunicação da UFRGS
\end{abstract}

Analisa a interação entre a produção científica e tecnológica dos pesquisadores que depositaram patentes na área da Biotecnologia. Objetiva revelar a co-autoria nos artigos e patentes publicados ou depositados pelos pesquisadores. Os resultados indicam que a co-autoria encontrada nas patentes se repete em $70,7 \%$ dos casos, nos artigos. Observa-se que o número de instituições coautoras é menor no depósito da patente do que na publicação dos artigos relacionados a ela.

Palavras-chave: Cientometria; Coautoria; Coinvenção; Interação C\&T.

\section{Coauthorship in articles and patents: interactions among scientific and technological production}

The article analyzes the interaction between the scientific and technological production of researchers who have deposited patents in the field of Biotechnology. It aims to reveal the co-occurrence of co-authorship in article and patent published or filed by the researchers. The results

\footnotetext{
Este artigo é parte da tese de doutorado, intitulada "A interação entre artigos e patentes: um estudo cientométrico da comunicação científica e tecnológica em biotecnologia", defendida no Programa de Pós-Graduação em Comunicação e Informação (PPGCOM/UFRGS).
} 
indicate that the co-authors of patent publications also appear in $70.7 \%$ of the article authorships. It is observed that the number of institutions where co-authors belong to is lower in patenting than in the publication of articles related to it.

Keywords: Scientometrics; Coauthorship; Coinvention; Interaction C\&T.

Recebido em 04. 07.2010 Aceito em 01.06.2011

\section{Introdução}

Patentes e artigos estão associadas a dois processos autônomos, porém, inter-relacionados: ciência e tecnologia (C\&T). Para a análise da interação entre a produção oriunda das duas esferas, faz-se necessário considerar as diferenças e pontos em comum entre esses tipos de documentos, que se iniciam na fase de elaboração e vão até a sua divulgação. Além disso, é relevante avaliar a colaboração entre os atores envolvidos - autores e inventores. Essa concepção embasa-se em Meyer (2000), para quem a interação entre C\&T pode ser observada, através de instrumentos (produção) e dos recursos humanos envolvidos.

Vários enfoques metodológicos foram desenvolvidos para explorar as relações entre C\&T, a partir dos inventores oriundos das universidades - autores/inventores (neste estudo, denominados co-ativos), geradores de conhecimento que publicam e também patenteiam (BHATTACHARYA; KRETSCHMER; MEYER, 2003; TIJSSEN, 2004; KLITKOU; NYGAARD; MEYER, 2007). Klitkou, Nygaard e Meyer (2007) estudaram a colaboração entre pesquisadores co-ativos na área de Carbono. Seus resultados confirmaram que inventores co-ativos são mais produtivos e reconhecidos do que seus colegas não-inventores, mostrando que a interação entre C\&T produz efeitos positivos na produtividade e no reconhecimento dos autores.

Outros estudos de interação entre C\&T focaram na análise de citações, como o de Tijssen, Buter e Van Leeuwen (2000), que constataram que artigos científicos altamente citados por patentes relatam avanços científicos que podem ser considerados como "ciência útil" em termos de sua contribuição para o desenvolvimento tecnológico. Os autores concluíram que muitas citações a artigos científicos nas patentes são atribuídas ao pesquisador-inventor e, provavelmente, se referem às ligações diretas, mas, não necessariamente, às relações causais entre C\&T.

A ciência é vista como um processo direcionado ao entendimento dos fenômenos, ao passo que a tecnologia é vista como uma atividade que objetiva criar artefatos. Enquanto a publicação de resultados das pesquisas é percebida como uma representação do trabalho científico, a atividade tecnológica se materializa no próprio artefato e sua 
representação é a patente (MEYER; BHATTACHARYA, 2004). Segundo os mesmos autores, essas diferenças são resultado de dois regimes de conhecimento predominantes e fundamentalmente distintos na ciência e tecnologia. A pesquisa científica é baseada em um regime de 'ciência aberta', no qual a ciência pode ser vista como um bem público, pois os resultados da pesquisa são livremente disseminados. A'ciência aberta' é tipicamente contrastada com o regime de 'tecnologia proprietária', no qual o conhecimento tem caráter de bem privado e sua disseminação está restrita, através de vários mecanismos, um dos quais é a patente. A característica mais importante encontrada no processo de construção do conhecimento científico é a discussão entre os pares, por meio da qual a pesquisa é divulgada e recebe críticas e sugestões de aprimoramento (CALLON; COURTIAL; PENAN, 1993). Por outro lado, no desenvolvimento de produtos ou processos, o pesquisador não divulga os resultados parciais ou finais do seu trabalho, até que a garantia da patente seja concedida. A manutenção do segredo não permite o debate crítico, a troca de ideias e de experiências entre cientistas, restringindo o livre fluxo de informações. Ou seja, patentes e artigos pertencem a duas esferas diferentes, que possuem dificuldades de interação, pois seus objetivos são diferentes.

Embora apresentem diferenças significativas, artigos e patentes são, na verdade, expressões da pesquisa, podendo, muitas vezes, ser produzidos pelas mesmas pessoas, grupos ou instituições, como destacado por Santos (2003):

Por fim, qualquer que seja a dimensão, na qual os pesquisadores estão engajados, ela somente se materializa na produção de documentos escritos. Quando pesquisadores elaboram pesquisas, eles produzem artigos; quando participam de processo de inovação, depositam patentes ou divulgam notas técnicas ou manuais de utilização; quando se envolvem com a docência, dirigem tese, elaboram manuais, apostilas; quando participam de programas públicos, redigem projetos para obter subvenções e relatórios justificando a utilização dos recursos [...] se consagram à popularização, elaboram livros, roteiros, contribuem para a redação de regulamentos, de pareceres... (SANTOS, 2003, p. 32)

Desta forma, questiona-se se a coautoria e coinvenção interpessoal e interinstitucional, que coocorre nestas expressões da pesquisa (artigo e patente), significam uma interação entre ciência e tecnologia. Para tanto, buscam-se as interfaces da produção científica e tecnológica na área da Biotecnologia, que se utiliza dos conhecimentos científicos, aliados à técnica necessária para intervenção e modificação na natureza, situandose, portanto, entre essas duas esferas.

A seguir, apresentam-se os procedimentos metodológicos utilizados neste estudo. 


\section{Procedimentos metodológicos}

Utilizou-se uma abordagem quantitativa, a partir de uma perspectiva cientométrica. Foram utilizados métodos estatísticos, aliados à Análise de Redes Sociais (ARS), que deram subsídio para entender os relacionamentos entre coautoria e coinvenção, expressas nos documentos de artigos e de patentes publicados ou depositados pelos sujeitos do estudo.

Os sujeitos constituem-se dos pesquisadores brasileiros, que possuem tanto pedidos de patentes como artigos publicados na área de Biotecnologia. A amostra foi formada por aqueles que possuem, pelo menos, um pedido de patente depositado na Base de Patentes do INPI e um artigo indexado na base WebofScience. O período selecionado para a análise das publicações compreende os anos de 2001 a 2005. Primeiramente, foi realizada uma busca na base de patentes do INPI pelos códigos de classificação utilizados para a área da Biotecnologia, conforme a Organisation for Economic Co-Operation and Development (OECD) (2005). Foram coletados 3.571 documentos, deste total, 3.327 eram patentes estrangeiras e 244 brasileiras. Após a padronização dos registros, restaram 2.331 estrangeiras, que não eram foco deste estudo, e 194 brasileiras, que foram analisadas. A produção científica dos sujeitos, recuperada e identificada no WebofScience, totalizou 4.288 artigos, que, após a supressão dos registros duplicados, reduziu-se para 2.584.

Os nomes das instituições e dos autores foram normalizados. Além disso, os coativos foram codificados da seguinte forma: COA1, COA2 e, assim, sucessivamente.

Para verificar indícios de interação entre ciência e tecnologia, utilizou-se a análise de coautoria e coinvenção, técnicas utilizadas na Cientometria. A partir da codificação dos coativos, foi possível identificar a sua vinculação a cada artigo e cada patente, identificando-se, assim, quando as coautorias se repetiam em patentes e artigos. Criou-se uma matriz, que possibilitou a análise de redes sociais e, também, foram realizadas análises estatísticas descritivas.

\section{Análise e discussão dos resultados}

Nesta seção, apresentam-se as análises de correlação entre artigos e patentes dos depositantes e dos coativos.

\subsection{Correlação entre artigos e patentes dos depositantes e autores coativos}

Para esta análise, foram utilizados apenas os depositantes que possuíam artigo e patente, ou seja, os depositantes coativos. A partir do número de ocorrências de artigos e patentes de cada depositante, observou-se a existência de correlação significativa, através da correlação 
de Pearson. Esta análise teve como objetivo verificar se os depositantes que mais publicaram artigos eram, também, os mais produtivos em patentes. A correlação entre artigos e patentes dos depositantes coativos é significativa $(p<0,005)$, com as universidades figurando no topo das listas de frequências, tanto em artigos como em patentes. A produtividade máxima dos depositantes coativos em artigos e patentes é de 1.149 artigos para o depositante coativo mais produtivo em ciência e 27 patentes para o depositante coativo mais produtivo em tecnologia. A configuração do gráfico abaixo, mostra o resultado da análise (GRÁF. 1).

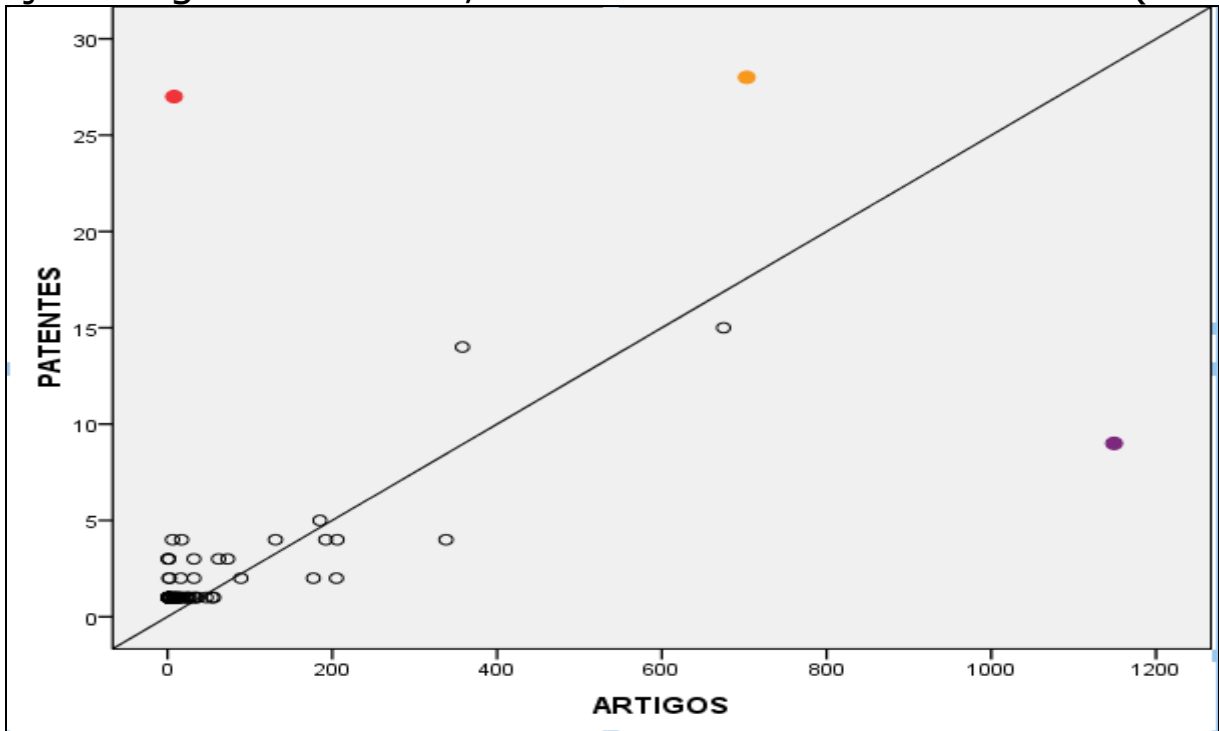

GRÁFICO 1 - Dispersão artigos/patentes depositantes coativos

Fonte: Dados da pesquisa.

Observa-se uma concentração muito grande de patentes e artigos na junção dos dois eixos, mostrando que o núcleo de produção de artigos está mais forte entre 1 e 100 artigos e o núcleo de produção de patentes, entre 1 e 4. Constata-se a existência de casos atípicos, que podem interferir no resultado da análise: FAPESP (cor vermelha), com 27 patentes, mas com apenas 8 artigos; e USP (cor roxa), com 1149 artigos, mas apenas 9 patentes; USP, que destoa na produção de artigos por possuir uma inclinação à pesquisa e não à tecnologia (SCHWARTZMAN, 2006), ao contrário da UNICAMP, que possui este duplo objetivo, mas com maior ênfase à produção de tecnologia; UNICAMP (cor laranja), possui 703 artigos e 28 patentes, mas se aproxima da linha de crescimento, próximo ao meio do gráfico. Se os dados referentes à USP, FAPESP e UNICAMP fossem retirados da análise, certamente a correlação seria ainda mais positiva. Em relação à FAPESP, salienta-se que esta instituição de fomento obrigava as instituições financiadas a dividirem a titularidade das patentes, condição que deixou de existir em 2006.

Quanto aos autores coativos, a produtividade máxima identificada é de 69 artigos para o autor coativo mais produtivo em ciência e quatro patentes para o inventor coativo mais produtivo em tecnologia. A correlação de Pearson mostrou-se significativa ao nível de 0.01, significando que os artigos são uma variável dependente das patentes. 
Representa-se a correlação graficamente, onde se destaca a linha que ilustra o crescimento linear das patentes, acompanhando o crescimento dos artigos (GRÁF. 2).

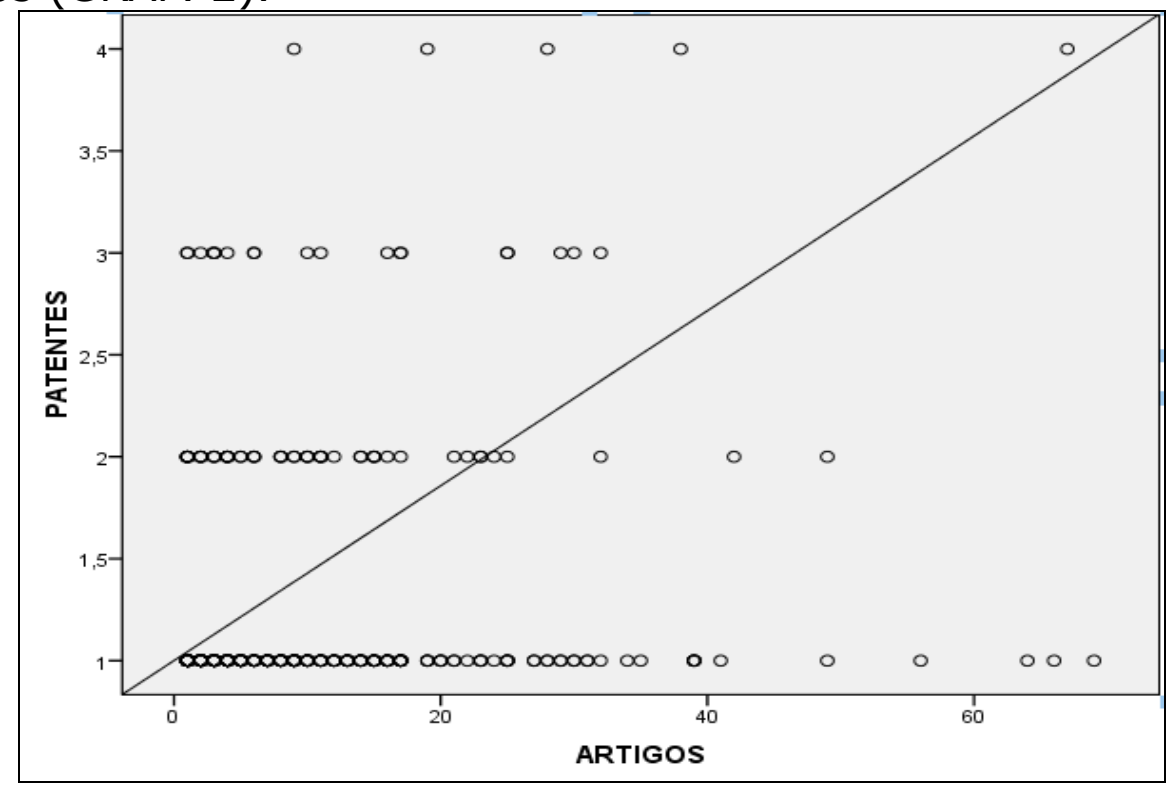

GRÁFICO 2 - Dispersão artigos/patentes por coativos

Fonte: Dados da pesquisa.

Desta forma, as análises de correlação dos depositantes e autores coativos possibilitam que se conclua que os autores e instituições coativos que mais possuem patentes são, também, aqueles que mais publicam artigos, indicando uma retroalimentação entre C\&T.

\subsection{Análises de coocorrência da coautoria interpessoal e interinstitucional}

Com o objetivo de verificar se as parcerias formadas durante a elaboração da patente repetem-se nas coautorias em artigos, realizaramse análises de correlação. Estas análises identificaram a vinculação dos coativos nos dois tipos de documentos, juntamente com os parceiros na publicação. Destaca-se que somente as coautorias que possuíam coativos foram analisadas, ou seja, as patentes que possuíam somente inventores foram excluídas das análises.

A FIG. 1 demonstra a rede de interação entre artigos e patentes, evidenciando apenas as patentes que possuem $\geq 2$ laços com artigos. 


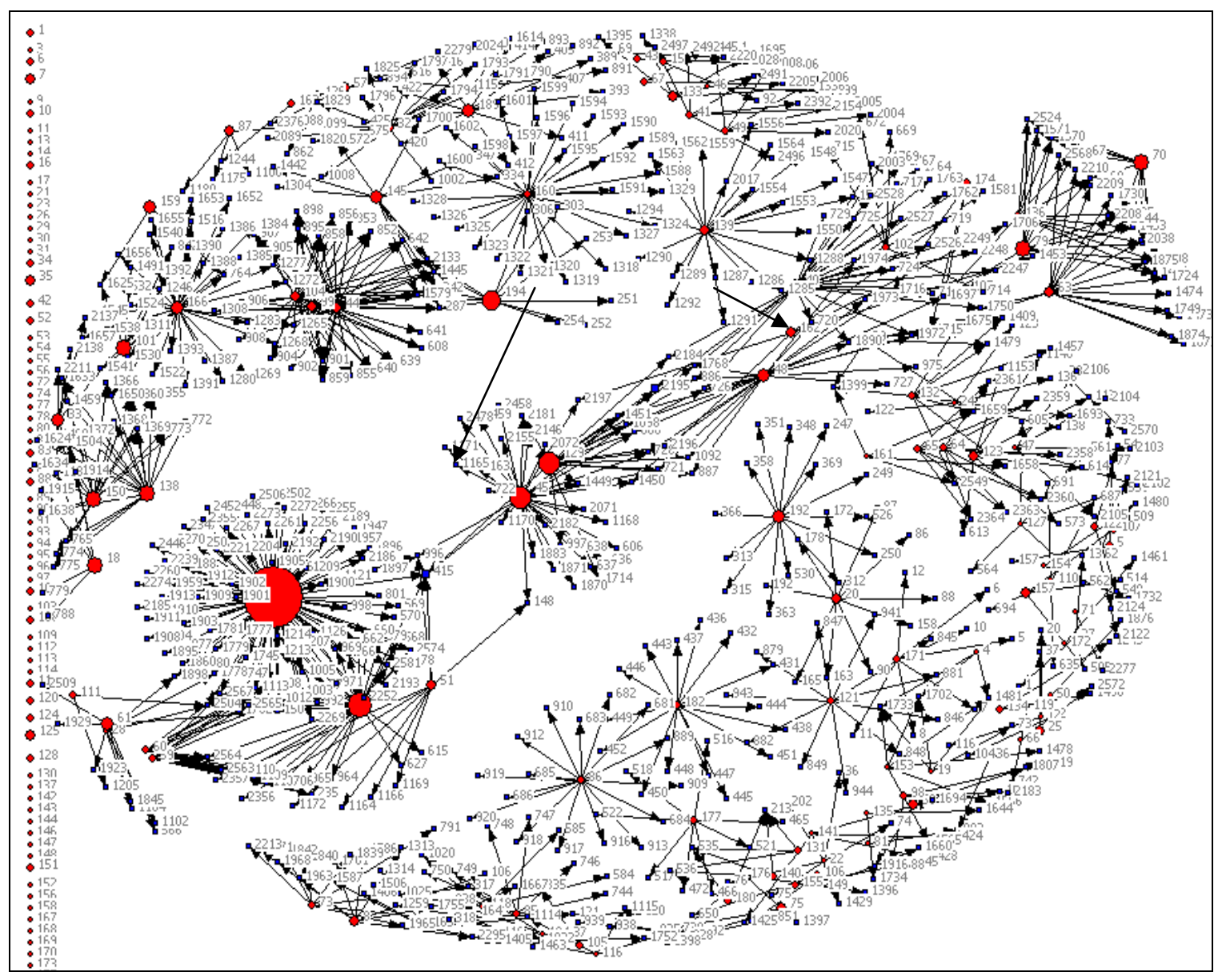

FIGURA 1 - Rede patentes e artigos - corte: $\geq 2$ laços

Fonte: Dados da pesquisa.

Esta rede mostra as pequenas redes interligadas à rede maior, embora existam várias redes isoladas. À esquerda, encontram-se as patentes isoladas, que não possuem o mínimo de dois laços para participar da rede. A apresentação desta rede mostra-se fracamente conectada, com cada patente formando um cluster ao seu redor, com alguns casos em que os mesmos artigos interligam-se a mais de uma patente. Esta formação de rede, com várias redes satélites, desconectadas, assemelha-se à configuração de redes típica da área da tecnologia, conforme os estudos de Meyer e Bhattacharya (2004). À direita, está o cluster formado pelas patentes 70, 63 e 79, cujas coautorias repetem-se. Bem ao centro da rede e mais a direita, também se verificam agrupamentos de patentes, que compartilham os mesmos artigos.

Destaca-se o nó maior, que se refere à patente com maior centralidade na rede (68), à esquerda da FIG. 1, com 403 laços, ou seja, 403 artigos possuem relação com esta patente através da coautoria. Observa-se que outras patentes aproximam-se desta, a partir da coautoria compartilhada, ampliando as conexões da mesma. Esta patente está vinculada ao projeto Genoma, por isso este envolvimento com tantos coativos e, consequentemente, instituições e pesquisadores. 
A TAB. 1 apresenta as patentes que possuem 10 ou mais artigos vinculados a elas por meio da coautoria, independente do número de autores que se repetem, ou seja, privilegia aquelas que possuem maior número de artigos vinculados, não importando o percentual de coocorrência. A coluna $\mathrm{N}$. de Artigos refere-se ao número de artigos relacionados à patente pela coautoria e a coluna $\mathrm{N}$. de artigos em colaboração mostra o $\mathrm{n}$. de artigos em que mais de 2 coativos colaboram.

TABELA 1 - Patentes com $\geq 10$ artigos em colaboração vinculados

\begin{tabular}{|c|c|c|c|c|c|c|}
\hline Ranking & $\begin{array}{l}\text { Código da } \\
\text { Patente }\end{array}$ & $\begin{array}{c}\text { N. de } \\
\text { Coativos }\end{array}$ & $\begin{array}{c}\text { N. de } \\
\text { Artigos }\end{array}$ & $\begin{array}{l}\text { Média Artigo } \\
\text { por Coativo }\end{array}$ & $\begin{array}{c}\text { N. de Artigos } \\
\text { em } \\
\text { Colaboração }\end{array}$ & $\begin{array}{l}\text { Média Coativos } \\
\text { por artigo }\end{array}$ \\
\hline 1 & 68 & 51 & 403 & 7,9 & 92 & $\overline{1,8}$ \\
\hline 2 & 45 & 16 & 129 & 8,1 & 35 & 2,2 \\
\hline 3 & 76 & 16 & 144 & 9 & 31 & 1,9 \\
\hline 4 & 166 & 2 & 68 & 34 & 31 & 15,5 \\
\hline 5 & 40 & 10 & 58 & 5,8 & 27 & 2,7 \\
\hline 6 & 160 & 1 & 27 & 27 & 27 & 27 \\
\hline 7 & 44 & 3 & 34 & 11,3 & 26 & 8,7 \\
\hline 8 & 104 & 3 & 34 & 11,3 & 26 & 8,7 \\
\hline 9 & 99 & 3 & 36 & 12 & 25 & 8,3 \\
\hline 10 & 48 & 6 & 55 & 9,2 & 21 & 3,5 \\
\hline 11 & 139 & 3 & 37 & 12,3 & 21 & 7 \\
\hline 12 & 129 & 6 & 115 & 19,2 & 18 & 3 \\
\hline 13 & 138 & 3 & 73 & 24,3 & 17 & 5,7 \\
\hline 14 & 150 & 3 & 72 & 24 & 17 & 5,7 \\
\hline 15 & 63 & 9 & 45 & 5 & 16 & 1,8 \\
\hline 16 & 86 & 3 & 21 & 7 & 16 & 5,3 \\
\hline 17 & 182 & 3 & 22 & 7,3 & 15 & 5 \\
\hline 18 & 32 & 3 & 48 & 16 & 14 & 4,7 \\
\hline 19 & 59 & 3 & 21 & 7 & 14 & 4,7 \\
\hline 20 & 60 & 3 & 21 & 7 & 14 & 4,7 \\
\hline 21 & 192 & 6 & 58 & 9,7 & 14 & 2,3 \\
\hline 22 & 79 & 5 & 77 & 15,4 & 11 & 2,2 \\
\hline 23 & 121 & 3 & 16 & 5,3 & 11 & 3,7 \\
\hline 24 & 136 & 4 & 22 & 5,5 & 11 & 2,7 \\
\hline 25 & 145 & 4 & 61 & 15,3 & 11 & 2,7 \\
\hline 26 & 189 & 3 & 51 & 17 & 11 & 3,7 \\
\hline 27 & 194 & 4 & 92 & 23 & 11 & 2,7 \\
\hline 28 & 20 & 2 & 50 & 25 & 10 & 5 \\
\hline 29 & 70 & 6 & 81 & 13,5 & 10 & 1,7 \\
\hline
\end{tabular}

Fonte: Dados da pesquisa.

Nessa tabela (TAB. 1), a patente 68 figura em primeiro lugar no ranking, relacionando-se a 51 coativos, que publicaram 403 artigos. Destes 403 artigos, 92 foram escritos em coautoria entre pelo menos dois dos coativos, alcançando uma média de 1,8 coativo por artigo colaborado. Esta patente não possui nenhum artigo que tenha sido escrito por todos, 0 
que é justificado pelo alto número de coautores envolvidos. Além disso, ela relaciona-se a 70 artigos, que foram escritos por dois coativos, 16 que foram escritos por três, um por quatro e três artigos que foram escritos por 5. Os 51 autores coativos ligados a ela estão vinculados a diversas instituições, reunidas a partir da Rede Nacional do Projeto Genoma Brasileiro, em torno do projeto GENOMA (MINISTÉRIO DA CIÊNCIA E TECNOLOGIA, 2008). A patente foi depositada pelo CNPq, em 2004. Como o projeto GENOMA envolve instituições separadas geograficamente, justifica-se porque as coautorias acontecem mais com poucos autores, pois a colaboração fica facilitada pela proximidade geográfica, já constatado por Katz (1994).

Outras patentes que merecem destaque, pelo número de coativos envolvidos, são as de número 45 e 76. A patente 45 foi depositada pela FAPESP em 2004, e apresenta 16 coativos vinculados, que produziram 129 artigos, sendo que 35 foram em colaboração, em uma média de 8,1 artigo por coativo. A patente 76 também apresenta 16 coativos envolvidos, que produziram 144 artigos, sendo que destes, 31 foram com algum tipo de colaboração.

Observa-se que as patentes que apresentam maior número de coativos são aquelas que apresentam maior número de artigos, proporcionalmente. Porém, as maiores médias de artigos por coativo pertencem aos coativos vinculados às patentes com menor número de inventores (coativos), como é o caso da patente 129, com 6 coativos, 115 artigos (média de 19,2 artigos por coativo); patente 138, com 3 coativos, 73 artigos (média de 24,3 artigos por coativo); patente 79, com 5 coativos, 77 artigos (média de 15,4 artigos por coativo); patente 145, quatro coativos, 61 artigos (média de 15,3 artigos por coativo) e patente 194, 4 coativos, 92 artigos (média de 23 artigos por coativo). Desta forma, constata-se que as menores equipes são as mais produtivas.

$\mathrm{Na}$ TAB. 2, apresenta-se o resultado da análise de coocorrência entre os artigos e patentes a partir dos autores (coativos). Na coluna Total de Artigos: o número de artigos que estes coativos produziram, não necessariamente todos juntos; Artigos todos autores: o número de artigos em que todos os coativos publicam juntos; CO-1: número de artigos em que apenas um coativo aparece; CO-2: número de artigos em que dois coativos aparecem; CO-3: número de artigos em que três coativos aparecem; CO-4: número de artigos em que quatro coativos aparecem, maior coocorrência encontrada.

TABELA 2 - Patentes relacionadas a 4 ou mais artigos publicados por todos coautores

\begin{tabular}{clllcccc}
\hline 177 & 2 & 21 & 8 & 13 & 8 & 0 & 0 \\
86 & 3 & 21 & 7 & 5 & 9 & 7 & 0 \\
99 & 3 & 36 & 7 & 11 & 18 & 7 & 0 \\
49 & 2 & 20 & 6 & 14 & 6 & 0 & 0 \\
41 & 2 & 25 & 6 & 19 & 6 & 0 & 0 \\
64 & 2 & 12 & 6 & 6 & 6 & 0 & 0 \\
65 & 2 & 12 & 6 & 6 & 6 & 0 & 0 \\
\hline
\end{tabular}




\begin{tabular}{cccccccc}
\hline 85 & 2 & 23 & 6 & 17 & 6 & 0 & 0 \\
115 & 2 & 18 & 6 & 12 & 6 & 0 & 0 \\
28 & 2 & 7 & 5 & 2 & 5 & 0 & 0 \\
44 & 3 & 34 & 5 & 8 & 21 & 5 & 0 \\
47 & 2 & 7 & 5 & 2 & 5 & 0 & 0 \\
102 & 2 & 11 & 5 & 6 & 5 & 0 & 0 \\
104 & 3 & 34 & 5 & 8 & 21 & 5 & 0 \\
118 & 2 & 25 & 5 & 20 & 5 & 0 & 0 \\
121 & 3 & 16 & 5 & 5 & 6 & 5 & 0 \\
127 & 2 & 10 & 5 & 5 & 5 & 0 & 0 \\
141 & 2 & 7 & 5 & 2 & 5 & 0 & 0 \\
145 & 4 & 61 & 5 & 50 & 6 & 0 & 5 \\
87 & 2 & 35 & 4 & 31 & 4 & 0 & 0 \\
116 & 2 & 7 & 4 & 3 & 4 & 0 & 0 \\
174 & 2 & 11 & 4 & 7 & 4 & 0 & 0 \\
189 & 3 & 51 & 4 & 40 & 7 & 4 & 0 \\
\hline
\end{tabular}

Fonte: Dados da pesquisa.

A TAB. 2 apresenta as patentes cujos inventores (coativos) se repetem na íntegra, em pelo menos quatro artigos. O número máximo de coautores encontrado é quatro. A patente 166 possui somente dois coativos: COA370 e COA371, que publicaram 68 artigos, sendo que destes, 31 são em coautoria entre os dois coativos. Embora a FAPESP seja a depositante, a instituição de origem destes coativos é a USP. A segunda patente que possui mais artigos relacionados é a de número. 20, depositada em 2005, pela UNICAMP. Ela possui dois coativos envolvidos, sendo que estes publicaram 50 artigos, 10 em coautoria. Esta tabela privilegia as patentes que possuem um número menor de coativos, demonstrando, novamente, que a repetição da coinvenção na coautoria ocorre com mais facilidade, quando as equipes são pequenas. Quando há um grande número de coativos nas patentes, esta coautoria tende a não se repetir integralmente nos artigos.

A TAB. 3 apresenta os artigos que possuem $\geq 71 \%$ de correlação total na coautoria entre patente e artigo. A ordenação escolhida foi pela maior porcentagem de coocorrência de coautoria, dando destaque aos casos em que ocorre maior interação entre artigo e patente a partir da co-autoria.

TABELA 3 - Patentes com $\geq 71 \%$ correlação total na coautoria entre patente e artigo

\begin{tabular}{|c|c|c|c|c|c|c|c|}
\hline $\begin{array}{l}\text { Código } \\
\text { Patente }\end{array}$ & $\begin{array}{l}\text { Ano } \\
\text { Patente }\end{array}$ & Instituição & Coativos & $\begin{array}{l}\text { Código } \\
\text { Artigo }\end{array}$ & $\begin{array}{c}\text { Ano } \\
\text { Artigo }\end{array}$ & Instituição & $\begin{array}{l}\text { \% Correlação } \\
\text { na Coautoria }\end{array}$ \\
\hline 176 & 2002 & EMBRAPA & $\begin{array}{l}\text { COA379 } \\
\text { COA380 }\end{array}$ & 1396 & 2005 & EMBRAPA & 100 \\
\hline & & & & $\begin{array}{l}1397 \\
1398\end{array}$ & $\begin{array}{l}2005 \\
2002\end{array}$ & $\begin{array}{l}\text { EMBRAPA } \\
\text { EMBRAPA }\end{array}$ & \\
\hline 154 & 2002 & $\begin{array}{l}\text { Transcells } \\
\text { Prod. Distrib. } \\
\text { Células e }\end{array}$ & $\begin{array}{l}\text { COA352 } \\
\text { COA353 } \\
\text { COA354 }\end{array}$ & 1480 & 2004 & PUCPR & 100 \\
\hline
\end{tabular}




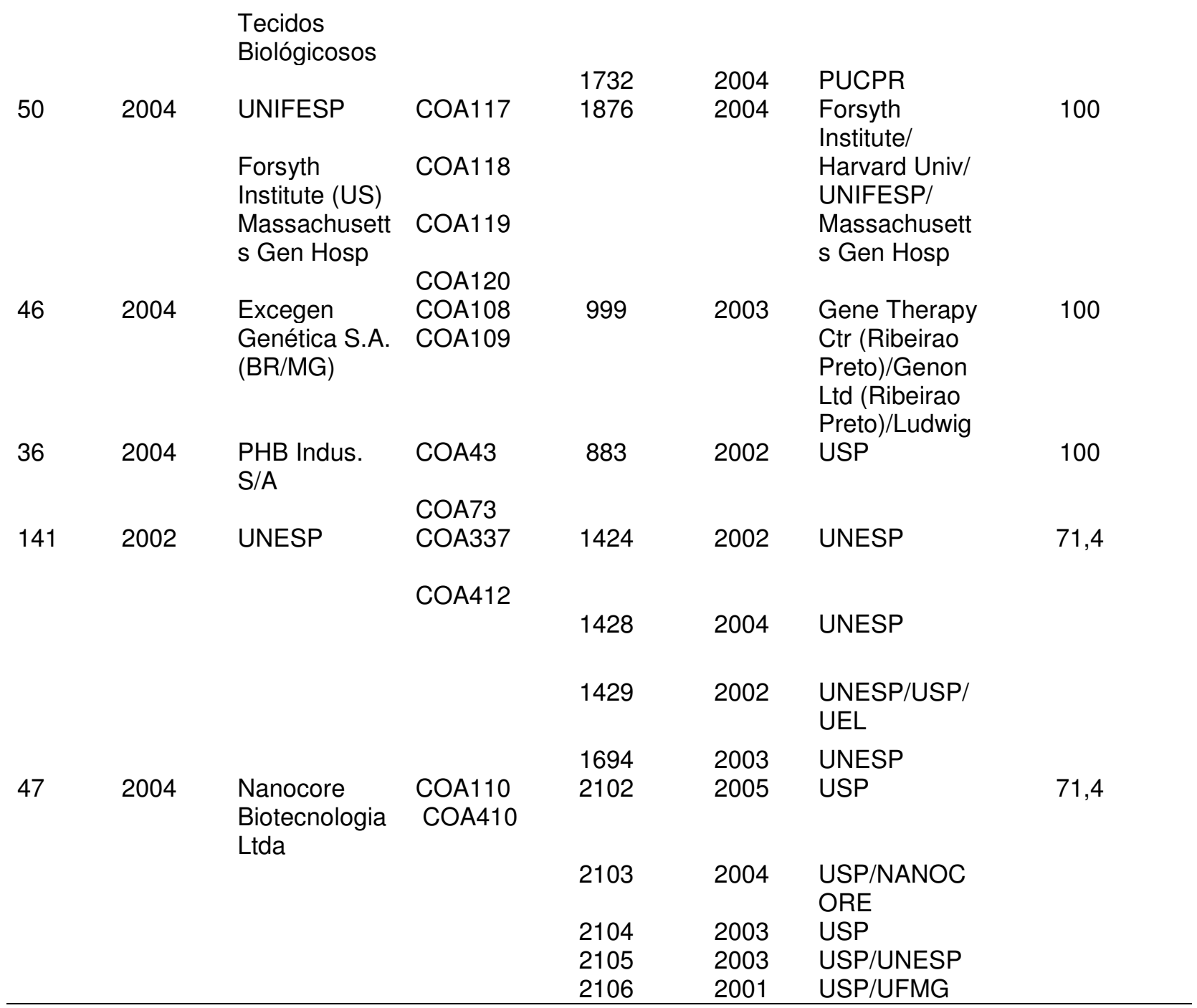

Fonte: Dados da pesquisa.

Observa-se que cinco patentes possuem uma coocorrência total $(100 \%)$ entre os artigos e as patentes, o que significa que as parcerias se repetem em ambas as publicações. A patente 176, cujo ano de depósito é 2002, possui dois coativos vinculados, sendo que estes, no mesmo ano da patente, publicaram juntos um artigo e, em 2005, dois artigos. Estes coativos são: COA379 e COA380, vinculados à EMBRAPA (Cerrados), depositante da patente. Os três artigos foram publicados no mesmo periódico, publicação própria da instituição. A patente 50 , que também apresenta $100 \%$ de coocorrência dos autores em um dos artigos publicados pelos coativos possui as mesmas instituições de vínculo na patente e nos artigos, sendo que nesses, foi acrescentada mais uma estrangeira, a Harvard University. Observa-se que a maioria das instituições colaboradoras são estrangeiras, e o tema é o uso de células tronco em Odontologia.

Comparando-se as instituições depositantes de patentes e as de vínculo dos autores dos artigos, observa-se que o número de instituições é menor quando no depósito da patente, aumentando na publicação dos artigos relacionados a ela. Como exemplo, destaca-se a patente de 
número 46, depositada somente pela Excegen Genética S.A., em 2004 e em 2003, os dois coativos inventores desta patente publicaram um artigo com outras três instituições: Gene Therapy Ctr, Genon e Ludwig, sendo que a depositante da patente não participou deste artigo. A patente 92 também apresenta maior número de instituições nos artigos, comparando-se ao número de depositantes: como depositante, aparece somente a UNICAMP, e nos artigos, UNICAMP, USP, APTA, EMBRAPA, INST BOT. Neste caso, a depositante está incluída no vínculo da autoria do artigo.

Estas análises demonstram que a coautoria em ciência é muito mais fácil de acontecer e de estabelecer relações interinstitucionais do que a coautoria (coinvenção) em patente, mais intramural e restrita a quem realmente produziu a patente, como já havia sido sugerido por Meyer e Battacharya (2004) e Ducor (2000).

Outro destaque é em relação à instituição depositante. Observa-se que na publicação dos artigos referentes a uma patente, ou seja, os artigos publicados pelos inventores da mesma, as instituições de vínculo dos coativos envolvidos são geralmente uma universidade ou instituto de pesquisa, não havendo a participação da empresa que possui a titularidade da patente, com uma única exceção, a patente 47 , que será detalhada na sequência. O que leva à conclusão que os coativos estão, em sua maioria, vinculados às instituições de ensino e pesquisa, e a parceria com as empresas ocorreu no desenvolvimento da patente, não mais se repetindo nos artigos. Talvez o fato das empresas não participarem da parceria nos artigos pode significar que para elas, a publicação não é tão importante como para os pesquisadores vinculados às instituições de ensino e pesquisa. Com relação à patente 47 , depositada pela Nanocore Biotecnologia Ltda, em 2004, apenas no artigo de 2004 aparece a Nanocore como instituição de vínculo. Os outros quatro artigos estão vinculados à USP, USP/UNESP e USP/UFMG. Esta empresa originou-se de um projeto de pesquisa de pesquisadores vinculados à UFMG e USP, o que a diferencia de outras empresas e caracteriza seu vínculo com a academia. Nos casos em que as instituições de ensino e pesquisa são depositantes, elas também participam da coautoria institucional nos artigos publicados pelos coativos. É o caso da patente 176 , que possui a EMBRAPA como depositante e instituição de vínculo nos artigos.

Cabe ressaltar aqui que, das 194 patentes que fizeram parte do estudo, 157 possuem coativos como inventores, sendo estas as patentes que fizeram parte das análises de coautoria e coclassificação. Destas 157, 111 possuem artigos com coautoria, que se repetem nas publicações científicas, atingindo um percentual de $70,7 \%$ de interação entre a produção científica e tecnológica. Assim, apenas 29,3\% das patentes não apresentam nenhuma relação de coautoria entre artigo e patente, percentual que pode ser explicado pelo fato do período estudado ser de apenas cinco anos (2001 a 2005). Isto porque existe um período de sigilo de 18 meses, após o depósito do pedido de patente, quando os dados referentes àquela patente não podem ser divulgados. Porém, este prazo tem-se mostrado bem maior, devido aos atrasos do INPI para analisar o 
processo depositado. Em relação ao percentual total de patentes (194), incluindo aqui, também as patentes que não possuem coativos, o percentual de interação diminui para 57,2\%.

Assim, pode-se concluir que a coautoria encontrada nas publicações de patentes se repete nas publicações científicas, indicando uma interação entre C\&T.

\section{Conclusão}

Conclui-se que os autores e instituições coativos, que mais possuem patentes são, também, aqueles que mais publicam artigos, pois as análises de correlação apresentaram-se significativas entre artigos e patentes. Esse resultado, quando entendido no contexto de autores que possuem tanto patentes quanto artigos publicados, contesta a crença de que a atuação em ciência e em tecnologia é tarefa excludente, contraditória ou de competição.

Conclui-se que a coautoria encontrada nas publicações de patentes se repete nas publicações científicas, indicando uma interação entre C\&T. Nos casos de patentes com grande número de coativos envolvidos, esta coautoria tende a não se repetir integralmente nos artigos. Observa-se que cinco patentes possuem uma coocorrência total $(100 \%)$ na coautoria entre os artigos e as patentes, fortalecendo a conclusão de que se tratam de tipos de documentos diferentes para os mesmos resultados da pesquisa.

Comparando-se as instituições depositantes de patentes e as de vínculo dos autores dos artigos, observa-se que o número de instituições é menor no depósito da patente do que na publicação dos artigos relacionados a ela, o que confirma que a coautoria em ciência é muito mais fácil de acontecer e de gerar relações interinstitucionais do que a coautoria (coinvenção) em patente, mais intramural e restrita a quem realmente produziu a patente.

Observa-se que as patentes que mais possuem convergência na coautoria são aquelas que possuem menor número de coativos. Os motivos para que isto ocorra poderão ser elucidados em estudos qualitativos que revelem os motivos reais para a formação de parcerias na co-autoria em C\&T.

Uma questão que instiga estudos futuros é compreender os motivos da pequena participação das empresas depositantes de patentes na coautoria dos artigos publicados pelos coativos inventores. $O$ senso comum leva a crer que seu interesse limita-se à propriedade intelectual, que pode ser comercializada, mas é necessário entender porque as empresas não buscam, também, a acumulação de capital simbólico, o que poderia ser revertido em outras formas de poder ou na obtenção de poder econômico adicional.

Observou-se a ocorrência de colaboração entre instituições de ensino, pesquisa e empresas, assim como a existência de projetos com participação de inúmeras instituições e países, atuando em rede. A grande aplicabilidade das pesquisas, verificada no patenteamento do 
conhecimento, é resultado do recorte realizado, que partiu da produção intelectual dos pesquisadores que tinham patente depositada. Este procedimento foi proposital e adotado por se tratar de uma área com notória aplicabilidade tecnológica.

Conclui-se, então, que os resultados deste estudo rejeitam a linearidade e separação entre ciência e tecnologia, pois os atores não se movimentam de acordo com modelos lineares, hierárquicos, sequenciais, da pesquisa para o desenvolvimento, deste para a inovação e desta para o uso. Eles, também, rejeitam a noção de que ciência e tecnologia são campos incompatíveis ou antagônicos. Ciência e tecnologia se retroalimentam, pois seus atores pesquisadores (coativos) transitam entre as duas esferas, repetindo as parcerias e construindo o conhecimento científico e tecnológico, em um processo constante de interação.

\section{Referências}

BHATTACHARYA, S.; KRETSCHMER, H.; MEYER, M. Characterizing intellectual spaces between science and technology. Scientometrics, Dordrecht, v. 58, n. 2, p. 369-90, 2003.

CALLON, M.; COURTIAL, J-P.; PENAN, H. La Scientométrie. Paris: Presses Universitaires de France, 1993.

DUCOR, P. Intellectual Property: coauthorship and coinventorship. Science, v. 289, n. 5481, p. 873-75, Aug. 2000.

KATZ, J. S. Geographical proximity and scientific collaboration. Scientometrics, Dordrecht, v. 31, n. 1, p. 31-43, 1994.

KLITKOU, A.; NYGAARD, S.; MEYER, M. Tracking techno-science networks: a case study of fuel cells and related hydrogen technology R\&D in Norway. Scientometrics, Dordrecht, v. 70, n. 2, p. 491-518, 2007.

MEYER, Martin. What is special about patent citations? Differences between scientific and patent citations. Scientometrics, Dordrecht, v.49, n.1, p.93-123, 2000b.

MEYER, M.; BHATTACHARYA, S. Commonalities and differences between scholarly and technical collaboration. Scientometrics, Dordrecht, v. 61, n. 3, p. 443-56, 2004.

ORGANISATION FOR ECONOMIC CO-OPERATION AND DEVELOPMENT. Science, technology and industry scoreboard 2005 : towards a knowledgebased economy. OECD, 2005. Disponível em: < http://puck.sourceoecd.org/vl=2684462/cl=21/nw=1 /rpsv/scoreboard/index.htm > Acesso em: 17 set. 2007.

SANTOS, R. N. M. Produção científica: por que medir? O que medir? Revista Digital de Biblioteconomia e Ciência da Informação, Campinas, v. 1, n. 1, p. 22-38, jul./dez. 2003.

SCHWARTZMAN, S. A Universidade Primeira do Brasil: entre intelligentsia, padrão internacional e inclusão social. Estudos Avançados, São Paulo, v. 
20, n. 56, p. 161-189, 2006. Disponível em: $<$ http://www.scielo.br/scielo.php?pid=S010340142006000100012\&script=sci arttext>. Acesso em: 07 jun. 2010.

TIJSSEN, R. J. W. Measuring science-technology interactions. In: MOED, H. F.; GLÄNZEL, W.; SCHMOCH, U. (Eds.). Handbook of quantitative science and technology research. Netherlands: Kluwer Academic Publishers, 2004. p. 695-715.

TIJSSEN, R. J. W.; BUTER, R. K.; VAN LEEUWEN, T. N. Technological relevance of science: an assessment of citation linkages between patents and research papers. Scientometrics, Dordrecht, v. 47, n. 2, p. 389-412, 2000. 